\title{
QUANTITATIVE STEREOLOGICAL ANALYSIS OF GRAIN BONDS IN SNOW
}

\author{
By P. R. KRY* \\ (Eidg. Institut für Schnee- und Lawinenforschung, 726o Davos, Switzerland)
}

\begin{abstract}
A section-plane preparation technique and an operational definition of a snow grain bond are developed to allow the quantitative analysis of bonding in snow structure. Values for three-dimensional grain size, grain-bond size and number density, and related bonding measurements are presented for equitemperature metamorphosed snow. These results from mutually orthogonal planes within a given snow block show that the assumptions of randomness and isotropy of grain and grain-bond location and orientauniaxial plastic deformation of analysis from one plane, are satisfied to within $\pm 10 \%$ even after $30 \%$ uniaxial plastic deformation of the snow block. The idealization of a grain bond as a circular plane disk
yields self-consistent results. The yields self-consistent results. The number of bonds per grain cannot be accurately determined from twodimensional studies due to variations in the shape and size of snow grains within a given sample.

RÉsumé. Analyse stéréologique quantitative des liasons entre grains dans la neige. Une méthode permettant de préparer des sections et une hypothèse de travail définissant une liaison entre des grains ont été développées pour rendre possible une analyse quantitative des liaisons dans la structure de la neige. On présente des valeurs pour les 3 dimensions des grains, la grosseur des liaisons entre les grains et leur nombre par unité de volume ainsi que d'autres valeurs semblables, mesurées dans de la neige transformée à température constante. de $+10 \%$ près les hypothèses que mutuellement orthogonales d'un échantillon particulier confirment à plus qu, $\pm 10 \%$ près les hypothèses que les grains et les liaisons entre les grains soient répartis aléatoirement et un axe unique. Ces hypothèses dieu et d'orientation, même après une déformation plastique de $30 \%$ dans un axe unique. Ces hypothèses permettent l'analyse stéréologique d'une seule coupe. La liaison entre les grains idéalisée en disque plan ne contredit point les résultats. Il n'est pas possible de déterminer exactement le nombre de liaisons par grain par des études bidimensionnelles à cause de la variation de la forme et de la grosseur des grains dans un échantillon particulier.

Zusammenfassung. Quantitative sterologische Analyse von Kornbindungen in Schnee. Eine Methode zur Bearbeitung von Schnittfächen und eine Arbeitshypothese zur Definition einer Kornbindung wurden entwickelt um eine quantitative Analyse der Bindungsverhältnisse in der Schneestruktur zu ermöglichen. Dreidimensionale Werte für Korngrösse, Grösse der Kornbindung und Anzahl der Kornbindungen pro Volumeneinheit und verwandte Grössen sind dargestellt für unter homogenen Temperaturen umgewandelten Schnee. Die Resultate aus gegenseitig orthogonalen Schnittflächen einer gegebenen Schneeprobe zeigen, dass die Annahmen einer zufälligen Verteilung und Isotropie von Ort und Orientierung der Körner und Kornbindungen - welche für eine stereologische Analyse aus nur einer Schnittebene notwendig sind innerhalb einer Streuung von $\pm 10 \%$ erfüllt sind, sogar nach einer $30 \%$ igen einachsialen plastischen Verformung. Die Idealisierung einer Bindungsstelle als kreisförmige, ebene Scheibe ergibt in sich widernicht genau bestimmt Die Anzahl der Bindungen pro Korn kann aus zweidimensionalen Untersuchungen nicht genau bestimmt werden wegen der Variationen der Kornform und -grösse innerhalb einer gegebenen
Schneeprobe.
\end{abstract}

\section{INTRODUCTION}

Snow is a collection of ice grains interconnected in an intricate three-dimensional structure. The grain bonds between every two linked grains play an important role in determining those mechanical properties of snow which are structure dependent (Ballard and McGaw, 1965; Feldt and Ballard, I966; Keeler, 1969). This is not unexpected considering the stress concentrations that can exist due to the relative constriction of the ice in the neck regions of the grains. To assess the importance of grain bonds to mechanical properties quantitatively and thereby to gain an understanding of the nature of snow structure, values of the average size and number density of the bonds, and of the mean grain size must be measured.

The common method of analysing snow structure involves utilizing thin sections which are usually up to half the average grain size in thickness (Fuchs, I959; Quervain, I969; Keeler, 1969). However, due to the finite thickness of these sections the analysis is of a projected image of part of the snow structure. The stereological relationships needed to deduce threedimensional measurements from observations of a projected image are at present not well * Present address: Production Research and Technical Service Laboratory, Imperial Oil Limited, $339-50$ Ave.
S.E., Calgary, Alberta $T_{2} \mathrm{G}_{2} \mathrm{~B}_{3}$, Canada. 
developed (Underwood, 1970). Another technique (Quervain, 1948) involves the preparation of successive parallel plane surfaces in a block of snow (filled with frozen dodecanoic acid ethyl ester). The surface is cut with a microtome and then rubbed with a dye to make the grains visible. Once the surface has been photographed, a $100 \mu \mathrm{m}$ layer is shaved off to reveal the next plane. This time-consuming method yields a three-dimensional view of the interconnections of the grains, however, it cannot give measurements for grain bonds which are smaller than the shaving thickness. Narita (I97I) also used section planes cut through snow samples. He dyed the ice grains in order to evaluate the specific surface area of the snow grains (that is, the total surface area of the grains per unit volume of snow).

This paper describes a technique for the preparation of a plane surface on which the ice is outlined (a variant of the techniques used by Narita and Quervain), and presents an operational definition of a grain bond cut by such a section plane. Quantitative stereology is then applied to deduce grain-bonding information in three dimensions for rounded-grain snow samples from measurements made on section planes; the limitations of this information are outlined. The randomness of location and orientation of the structural features are studied by comparing the results of analyses of two mutually perpendicular planes in snow samples which have been deformed. Such deformations lead to anisotropy in the mechanical properties which could be reflected in bond properties. If the snow is isotropic then measurements from a single plane provide correct three-dimensional information, otherwise more than one plane must be analysed.

\section{Segtion-Plane PReparation teghnique}

Samples are cut from the snow to be analysed and slowly immersed in I,2-benzenedicarboxylic acid diethyl ester (Quervain, I969). The pore-filling material will freeze when nucleated or cooled to temperatures lower than $-30^{\circ} \mathrm{C}$. Its melting point is not well determined but it is near $-4^{\circ} \mathrm{C}$ and therefore the working environment should be colder than $-10^{\circ} \mathrm{C}$. A slab is cut from the frozen sample with a saw and attached to a glass slide by melting and then refreezing the pore filler. A thickness of three to four average grain diameters is then shaved off the slab with a microtome to produce the section plane. The important criterion for this plane surface is that away from the edges it should not contain grains which were disturbed by the first cutting of the sample. Once the section plane is cut, since ice has a much higher vapor pressure than the pore filler, evaporation begins from the ice and, in particular, from the ice-pore-filler boundary. After ro minutes in a cold environment at $-12{ }^{\circ} \mathrm{C}$ the fissures formed at this boundary appear to be of the order of $15 \mu \mathrm{m}$ deep. They are now filled with a fine potassium permanganate powder (grain size less than one micron) rubbed lightly over the surface.

Figure $I$ is a photograph of a section plane approximately $2.5 \times 4 \mathrm{~cm}^{2}$ in area. Figure 2 is a ro $\times$ magnified view of the surface which is suitable for evaluation. Since it is the ice which evaporates, the dark lines lie on ice next to the ice-pore-filler boundary. Air bubbles in the frozen pore-filler and holes left by ice grains dislodged during microtoming appear as dark areas. Figure I shows that very few grains are lost during the preparation of the plane. An advantage inherent in this technique is that more than one plane can be prepared from a single snow section by successively shaving off more layers, thereby increasing the statistical accuracy if this is necessary.

\section{Grain-BOND DEFINITION}

A grain bond is defined as the plane surface of minimum area situated in the neck region of two linked grains. The definition is partly subjective due to the complexity of possible grain shapes. However, observations of snow suggest a disk shape for most grain bonds. 


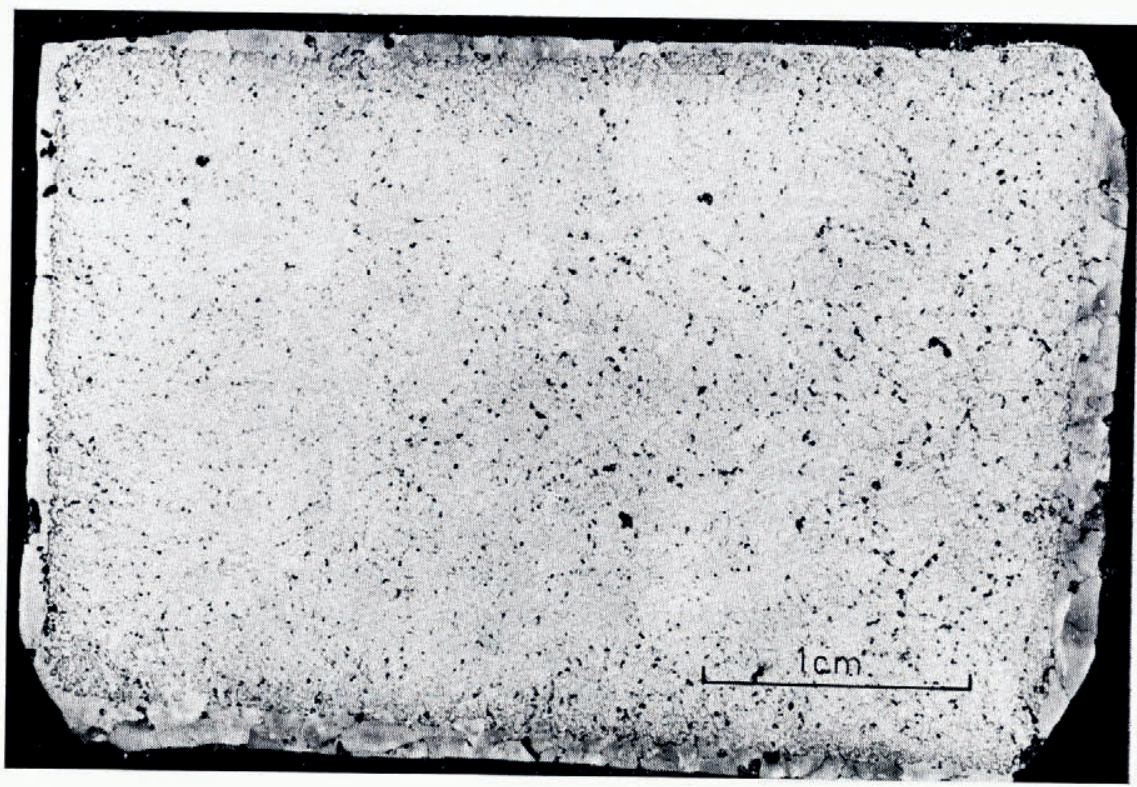

Fig. I. The prepared section plane of a snow sample.

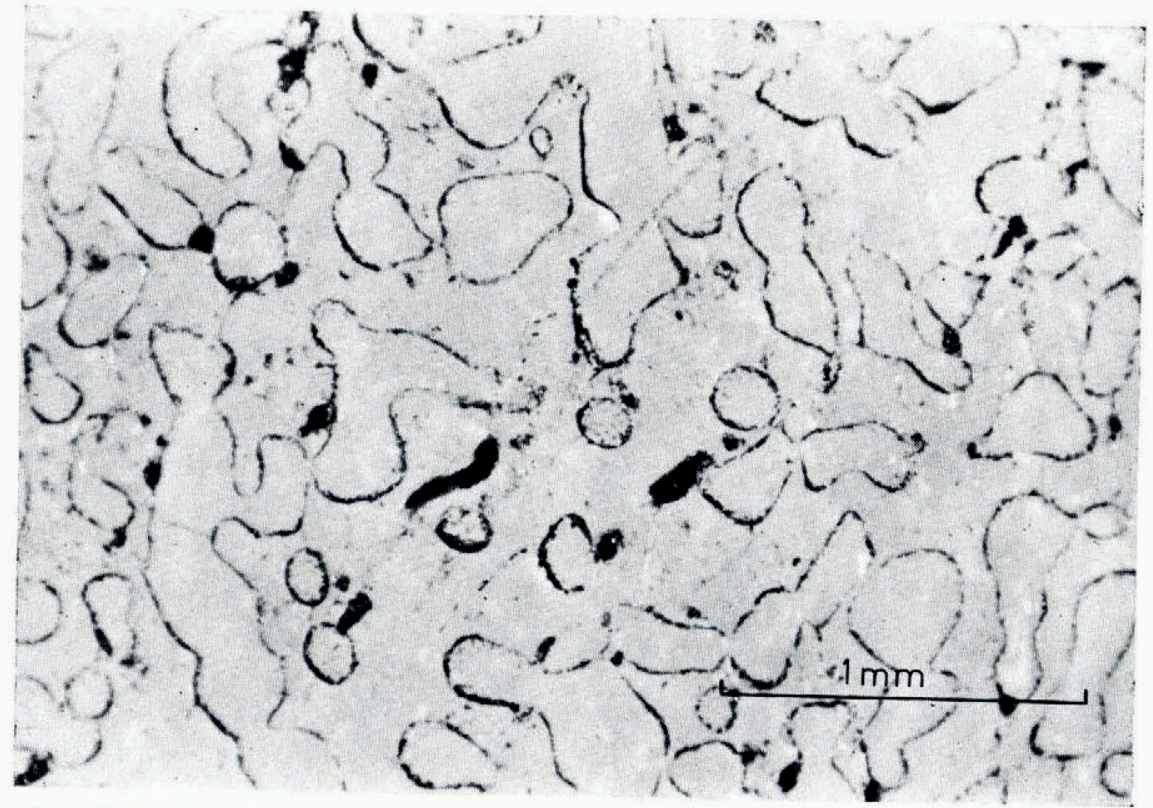

Fig. 2. Magnified portion of a section plane showing outlining of the snow phase with potassium permanganate powder. 
To suggest that the mechanical properties of snow can be analysed in terms of grain bonds presupposes the importance of these bonds. This supposition is primarily justified by the stress concentrations existing at grain bonds in stressed snow due to the relative constrictions in the ice. It is further justified by the observation that grain bonds are generally coincident with crystal bonds, the contact areas of crystals with differing $c$-axis orientations. Crystal bonds lie in a mechanically weak region compared with the adjacent ice crystals as a result of the extreme concentration of dislocations. Nevertheless, it must be realized that crystal bonds and grain bonds are not identical, merely coincident as a general rule. Single grains can be polycrystalline and, conversely, two adjacent grains can be part of the same crystal (Sommerfeld and LaChapelle, 1970).

If a grain bond is cut by a section plane it will appear as a straight line connecting two opposite edges of the ice. Three criteria are required to identify lines across the ice with grain bonds. First, a minimum relative constriction must exist; a $30 \%$ constriction on the plane is used as a cut-off as this corresponds to a decrease in the cross-sectional area of the ice at the grain bond by an order of magnitude. Secondly, both edges of the ice must show the constriction, both have a notch. Thirdly, the notches on each edge must pint approximately towards each other. The intersection of the grain bond and the section plane is the shortest line traversing the ice constriction. Experience has shown that all three criteria are essential to distinguish features due to grain bonds from those due to cuts through irregularly shaped grains. Figure 3 illustrates the application of this definition to a section plane. The eleven intersections of grain bonds with the section plane in the photograph are circled and indicated by a solid line.

These criteria still contain elements of subjectivity. However, in a given type of snow, errors due to this subjectivity are systematic and should not affect relative measurements. In the analysis of photographs (for example Figs 2 and 3 ) only the center $80 \%$ of the Figures is used for evaluation since grain bonds intersected by the section plane at the edges of the pictures cannot be identified with any certainty.

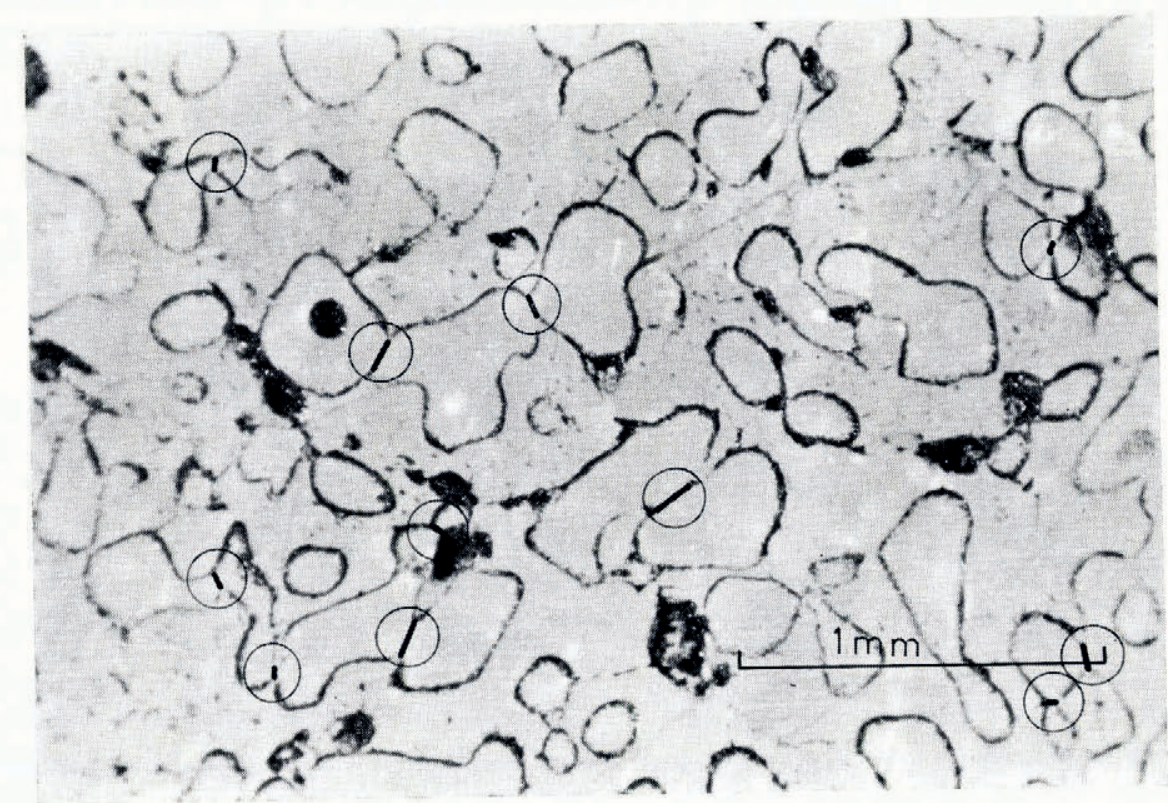

Fig. 3. Section plane with lines of the intersection of the surface with the bonds between snow grains indicated according to the operational definition. 


\section{Stereological Relations}

In the extensive literature review by Underwood (1970) stereological relations are developed and proved. Therefore, only final relationships and their necessary assumptions are presented in this section (apart from two derived relations not found elsewhere). One of these serves as a check of the assumption that the grain bonds are circular disks and the other provides the variance of the size distribution of a polydispersed system of disks.

The necessary general assumption which allows results from one section plane to give threedimensional information is randomness of location and orientation of the structural features in the three-dimensional network. The simplest measurements on the section plane involve counting intersections between specific features and test grids (Fig. 4). The grid of 24 test points yields a measure of $P_{\mathrm{p}}$, the fraction of the total number of test points on a grid (randomly placed over the plane) that fall within the ice, points which fall on boundaries count one-half (7.5/24 in Fig. 4). The accuracy of $P_{\mathrm{p}}$ is increased by summing the results of an application of the grid to different areas of the section plane. The grid of four test lines of total length $l$ yields $\mathcal{N}_{\mathrm{g}}$, the number of intersections of the ice-pore-filler boundary and a test line of unit length randomly placed over the plane (tangents counting one-half) $(30.5 / l$ in Fig. 4). A similar counting measure for grain bonds is $\mathcal{N}_{\mathrm{L}}$, the number of intersections of the lines representing bonds and a test line of unit length randomly placed over the plane (tangents counting one-half). A denser grid of lines (with longer total length) could be used so that the probability of a test line intersecting a grain bond would be increased. However, no purpose would be served if the test grid were so dense that each bond or grain were intersected several times. A statistical estimate of the errors in $P_{\mathrm{p}}, \mathcal{N}_{\mathrm{g}}$ and $\mathcal{N}_{\mathrm{L}}$ is the relative standard deviation of a Poisson distribution whose mean is equal to the number of points counted $(10 \%$ for 100 points).

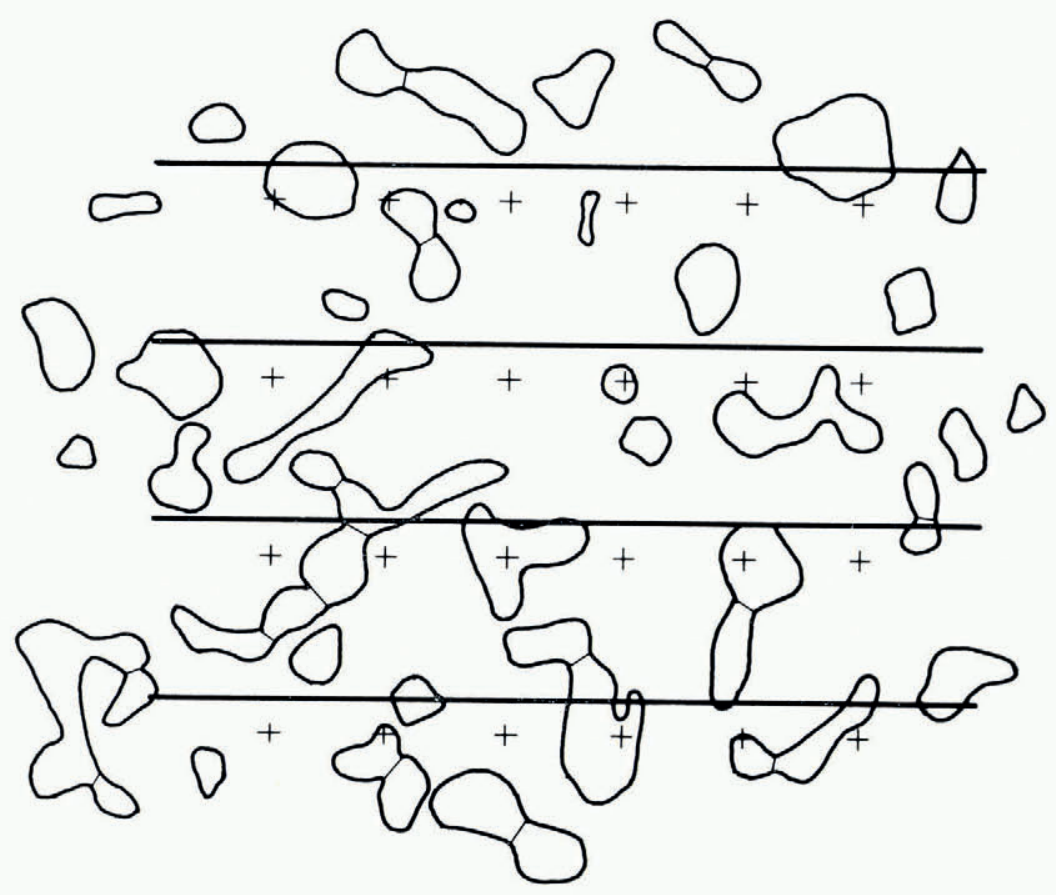

Fig. 4. Schematic section plane with superimposed grids of test points $(+)$ and test lines. 
The stereological relation between $P_{\mathrm{p}}$ and the snow density $\rho$ is expressed in terms of the ice density $\rho_{\mathrm{i}}$ as

$$
\rho=\rho_{\mathrm{i}} P_{\mathrm{p}}
$$

However, since snow density is usually more easily and accurately measured by weighing a given volume of snow, results from Equation (I) serve better as a check that the section plane is representative.

Without any further assumptions concerning grain shape or grain-size distribution, $\mathcal{N}_{\mathbf{g}}$ yields three-dimensional information about the grains. The total area of grain surface per unit volume is $2 \mathcal{N}_{\mathrm{g}}$ and $\beta_{\mathrm{g}}$, the mean random spacing between grains is $2 / \mathcal{N}_{\mathrm{g}}$. This mean random spacing is equivalent to the uninterrupted center-to-center length between all possible pairs of grains. The mean intercept length $L_{3}$, a statistical measure of three-dimensional grain size, is given by

$$
L_{3}=2 \rho /\left(\rho_{\mathrm{i}} \mathcal{N}_{\mathrm{g}}\right)
$$

For a single grain, $L_{3}$ is the average distance of a straight line through the grain from surface to surface. For a collection of grains this is extended to an average over all grains, yielding an average grain-size measurement. The mean-free-path from grain surface to grain surface is $d=\beta_{\mathrm{g}}-L_{3}$.

The stereological relationship between $\mathcal{N}_{\mathrm{L}}$ measured for the grain bonds and $S_{\mathrm{v}}$, the total area of grain bonds per unit volume is

$$
S_{\mathrm{v}}=2 \mathcal{N}_{\mathrm{L}} \text {. }
$$

Gurland (1958) defined the concept of contiguity as the fraction of three-dimensional grain surface shared with other grains. Contiguity $C$ is a measure of the short-range continuity of the ice expressed as

$$
C=\mathrm{I} /\left(\mathrm{I}+\left(\mathcal{N}_{\mathrm{L}} \beta_{\mathrm{g}}\right)^{-1}\right) \text {. }
$$

Quantitative statements about grain-bond number densities and mean size require an assumption of shape and two other measurements on the section plane. Fullman (1953) derived the necessary relations for the assumption that the grain bonds are circular disks. If $\mathcal{N}_{\mathrm{A}}$ is the number of grain bonds per unit area of the section plane and $E$ is the harmonic mean of the lengths of the lines representing grain bonds on that plane, then $\tilde{r}$, the mean three-dimensional radius of the grain bonds, and $\mathcal{N}_{\mathrm{v}}$, the number of grain bonds per unit volume are given by

$$
\begin{gathered}
\tilde{r}=4 /(\pi \bar{E}), \\
\mathcal{N}_{\mathbf{v}}=2 \mathcal{N}_{\mathrm{A}} /(\pi \tilde{r}) .
\end{gathered}
$$

It follows then that the mean grain-bond area is $A=S_{\mathbf{v}} / \mathcal{N}_{\mathbf{v}}$. A relationship which checks the assumption of a circular disk shape can be derived from the arithmetic mean of the lengths of the lines representing grain bonds on the section plane. Let the grain bonds be divided into classes with radii intervals sufficiently small so that all grain bonds in the same class may be assigned the same radius. Considering class $i$, designate $r_{i}$ as the grain-bond radius, $\mathcal{N}_{\mathrm{s} i}$ as the number of grain bonds cut by unit area of the section plane, $\mathcal{N}_{\mathrm{v} i}$ the number of grain bonds per unit volume and $\mathcal{N}_{\mathrm{L} i}$ the number of grain bonds intercepted by a test line of unit length. The arithmetic mean $\bar{\chi}_{i}$ of the lengths of the lines representing class $i$ grain bonds cut by the section plane is equal to the mean intercept length of a disk of radius $r_{i}$, that is

Fullman (1953) showed that

$$
\bar{\chi} i=\pi r_{i} / 2 .
$$

$$
\mathcal{N}_{\mathrm{si}}=\pi \mathcal{N}_{\mathrm{v} i} r_{i} / 2
$$

and that

$$
\mathcal{N}_{\mathrm{L} i}=\pi \mathcal{N}_{\mathrm{v} i} r_{i}{ }^{2} / 2
$$


The arithmetic mean of the lengths of all lines representing grain bonds on the section plane is written as

$$
\bar{\chi}=\sum \mathcal{N}_{\mathrm{s} i} \bar{\chi} i / \sum \mathcal{N}_{\mathrm{s} i}
$$

When Equations (7) and (8) are substituted in Equation (10) and then simplified using Equation (9), the checking relationship is found to be

$$
\mathcal{N}_{\mathrm{L}}=2 \bar{\chi} \mathcal{N}_{\mathrm{A}} / \pi \text {. }
$$

Values of $\mathcal{N}_{\mathrm{L}}$ calculated from Equation (I I) confirm or invalidate the circular disk assumption when compared with measured values.

The variance of the size distribution of the grain bonds is also expressed in terms of $\bar{\chi}$. The definition of the variance in terms of a summation over grain-bcnd size classes yields, after reduction,

$$
\sigma^{2}(r)=\frac{\mathcal{N}_{\mathrm{T}}}{\mathcal{N}_{\mathrm{T}}-\mathrm{I}}\left[\frac{\bar{A}}{\pi}-\bar{r}^{2}\right],
$$

where $\mathcal{N}_{\mathrm{T}}$ is the total number of grain bonds in the sample. As $\mathcal{N}_{\mathrm{T}}$ is usually very large, the first factor is essentially unity. When Equations (3) and (6) are used to substitute for $\bar{A}$, and Equation (II) is used to express this result in terms of $\bar{\chi}$, the relative standard deviation is expressed as

$$
\frac{\sigma(r)}{\tilde{r}}=\left[\frac{2 \bar{\chi}-\pi \tilde{r}}{\pi \bar{r}}\right]^{\frac{1}{2}} .
$$

Equation ( 13 ) indicates that if there is a size distribution of grain bonds then the arithmetic mean of the lengths of the intersections of the grain bonds with a section plane must be larger than the mean intercept length of the average grain bond. This is due to the larger bonds being more likely to be intercepted by the section plane and hence they weight the arithmetic mean length more heavily than do the shorter bonds.

\section{ANALysis OF EQUi-TEMPERATURE METAMORPHOSED SNOW}

Snow samples were prepared by sieving new or felt-like snow into $20 \times 20 \times 30 \mathrm{~cm}^{3}$ boxes and allowing the snow to sinter at a constant temperature $\left(-10^{\circ} \mathrm{C}\right)$ in the covered boxes for times between 20 and 60 days. Subsequently, snow blocks $5 \times 5 \times{ }_{1} \mathrm{~cm}^{3}$ were cut and non-destructively compressed uniaxially (along the long axis) by amounts up to $30 \%$. Stereological analyses were performed on planes parallel and perpendicular to the deformation direction.

Densities measured statistically from the section planes (a $P_{\mathrm{p}}$ count) agree with densities measured by weighing the snow samples (Fig. 5). The average densities of the snow samples from which the sections were cut were measured to within $\pm 2 \%$. The dotted lines in Figure 5 indicate the expected statistical error (relative standard deviation of a Poisson distribution with the mean equal to the number of points $(\approx 200)$ counted in the ice). The agreement between densities indicates that the section planes are representative of the snow samples.

Further results of the stereological analysis for five rounded-grain snow samples characterized by their densities appear in Table I. The results for the first sample are from three parallel planes of an undeformed sample. The four remaining samples were non-destructively deformed by $30 \%$ uniaxial strain. The four basic measurements $\left(\mathcal{N}_{\mathrm{g}}, \mathcal{N}_{\mathrm{L}}, \mathcal{N}_{\mathrm{A}}, E\right)$ on the section planes lead to values for $\beta_{\mathrm{g}}, S_{\mathrm{v}}, \mathcal{N}_{\mathrm{A}}$, and $\tilde{r}$ respectively. The first three are counting measurements and the expected statistical errors are, respectively, $\pm 7 \%, \pm 10 \%$, and $\pm 7 \%$, based on the numbers of features counted. The general procedure for a given plane was to evaluate two halves separately and then combine the results. The differences in the results for the two half-planes corresponded to the expected statistical errors. This difference is the only estimate of the error in $\dot{r}( \pm 6 \%)$. Errors in the other quantities in Table I are then estimated from the derived equations. These errors do not include a possible systematic 


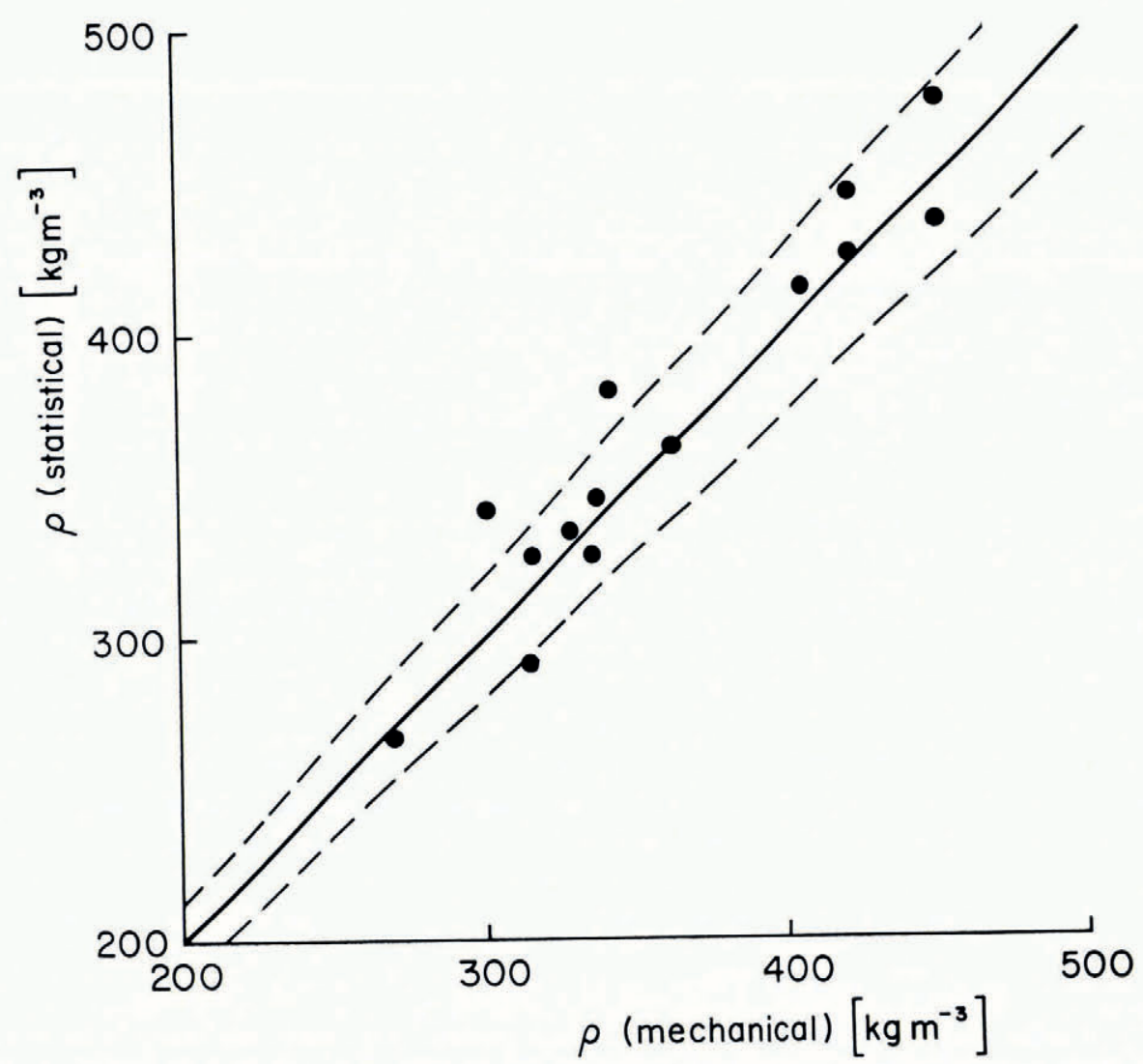

Fig. 5. Correspondence between snow sample density $\rho$ as measured both mechanically and statistically. The dotted lines indicate the expected statistical error.

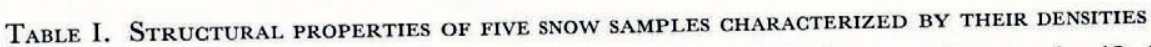

Three parallel planes of the first sample were evaluated. The remaining four samples were densified by $30 \%$ before planes parallel $(\|)$ and perpendicular $(\perp)$ to the densification direction were prepared and evaluated.

\begin{tabular}{|c|c|c|c|c|c|c|c|c|c|c|}
\hline$\stackrel{\rho}{\mathrm{kg} \mathrm{m}^{-3}}$ & $\begin{array}{c}L_{3} \\
\mathrm{~mm}\end{array}$ & $\underset{\mathrm{mm}}{d}$ & $\underset{\mathrm{mm}}{\beta_{\mathrm{g}}}$ & $C$ & $\underset{\substack{S_{\mathrm{v}} \\
\mathrm{mm}^{-1}}}{-}$ & $\begin{array}{c}\bar{r} \\
\mathrm{~mm}\end{array}$ & $\underset{\mathrm{mm}^{-2}}{\mathcal{N}_{\mathrm{A}}}$ & $\underset{\mathrm{mm}^{-3}}{\mathcal{N}_{\mathrm{v}}}$ & $\underset{\mathrm{mm}}{\bar{\chi}}$ & $\sigma(r) / \bar{r}$ \\
\hline $\begin{array}{l}33^{8} \\
338\end{array}$ & $\begin{array}{l}0.259 \\
0.261\end{array}$ & 0.44 & 0.70 & $\begin{array}{l}0.034 \\
0.036\end{array}$ & $\begin{array}{l}0.098 \\
0.105\end{array}$ & $\begin{array}{l}0.053 \\
0.064\end{array}$ & $\begin{array}{l}0.95 \\
0.88\end{array}$ & $\begin{array}{r}\text { I } 1.3 \\
8.8\end{array}$ & $\begin{array}{l}0.089 \\
0.106\end{array}$ & $\begin{array}{l}0.24 \\
0.23\end{array}$ \\
\hline $\begin{array}{l}33^{\circ} \\
33^{8}\end{array}$ & $0.26 \mathrm{I}$ & $\begin{array}{l}0.45 \\
0.45\end{array}$ & $\begin{array}{l}0.7 \mathrm{I} \\
0.7 \mathrm{I}\end{array}$ & $\begin{array}{l}0.03^{0} \\
0.04^{2}\end{array}$ & $\begin{array}{l}0.105 \\
0.124\end{array}$ & 0.053 & I. 14 & I 3.6 & 0.095 & $0.3^{6}$ \\
\hline $\begin{array}{l}\perp 369 \\
\|_{369}\end{array}$ & $\begin{array}{l}0.219 \\
0.230\end{array}$ & $\begin{array}{l}0.33 \\
0.34\end{array}$ & $\begin{array}{l}0.54 \\
0.57\end{array}$ & $\begin{array}{l}0.045 \\
0.046\end{array}$ & $\begin{array}{l}0.172 \\
0.169\end{array}$ & $\begin{array}{l}0.04^{2} \\
0.041\end{array}$ & $\begin{array}{l}\text { I. } 9^{8} \\
\text { г. } 9^{2}\end{array}$ & $\begin{array}{l}30.4 \\
29.9\end{array}$ & $\begin{array}{l}0.065 \\
0.070\end{array}$ & $\begin{array}{l}0.01 \\
0.30\end{array}$ \\
\hline $\begin{array}{l}\perp 406 \\
406\end{array}$ & $\begin{array}{l}0.207 \\
0.229\end{array}$ & $\begin{array}{l}0.26 \\
0.29\end{array}$ & $\begin{array}{l}0.47 \\
0.5^{2}\end{array}$ & $\begin{array}{l}0.048 \\
0.053\end{array}$ & $\begin{array}{l}0.218 \\
0.218\end{array}$ & $\begin{array}{l}0.043 \\
0.042\end{array}$ & $\begin{array}{l}2.26 \\
2.85\end{array}$ & $\begin{array}{l}33.8 \\
43.1\end{array}$ & $\begin{array}{l}0.072 \\
0.068\end{array}$ & $\begin{array}{l}0.26 \\
0.19\end{array}$ \\
\hline $\begin{array}{l}\perp 4^{21} \\
\| 4^{21}\end{array}$ & $\begin{array}{l}0.233 \\
0.246\end{array}$ & $\begin{array}{l}0.27 \\
0.29\end{array}$ & $\begin{array}{l}0.5^{1} \\
0.54\end{array}$ & $\begin{array}{l}0.067 \\
0.064\end{array}$ & $\begin{array}{l}0.282 \\
0.254\end{array}$ & $\begin{array}{l}0.046 \\
0.046\end{array}$ & $\begin{array}{l}2.3^{8} \\
2.62\end{array}$ & $\begin{array}{l}33 \cdot 3 \\
35 \cdot 9\end{array}$ & $\begin{array}{l}0.080 \\
0.077\end{array}$ & $\begin{array}{l}0.34 \\
0.23\end{array}$ \\
\hline $\begin{array}{r}\perp 445 \\
\|_{445}\end{array}$ & $\begin{array}{l}0.297 \\
0.293\end{array}$ & $\begin{array}{l}0.3^{2} \\
0.3^{1}\end{array}$ & $\begin{array}{l}0.6 \mathrm{I} \\
0.6 \mathrm{o}\end{array}$ & $\begin{array}{l}0.065 \\
0.070\end{array}$ & $\begin{array}{l}0.226 \\
0.25^{0}\end{array}$ & $\begin{array}{l}0.053 \\
0.057\end{array}$ & $\begin{array}{l}2.2 \mathrm{I} \\
2.2 \mathrm{I}\end{array}$ & $\begin{array}{l}26.7 \\
24.8\end{array}$ & $\begin{array}{l}0.086 \\
0.091\end{array}$ & $\begin{array}{l}0.18 \\
0.13\end{array}$ \\
\hline
\end{tabular}

$\rho$, snow density; $L_{3}$, mean intercept length; $d$, mean-free-path between grains; $\beta_{\mathrm{g}}$, mean random spacing; $C$, contiguity; $S_{\mathrm{v}}$, specific bond surface area; $\bar{r}$, mean bond radius; $\mathcal{N}_{\mathrm{A}}$, mean number of bonds intersected by a plane of unit area; $\mathcal{N}_{\mathrm{v}}$, number of bonds per unit volume; $\bar{\chi}$, arithmetic mean of the lengths of the intersections of bonds with a plane; $\sigma(r) / \bar{r}$, relative standard deviation of bond-size distributions. 
error due to subjectivity in the definition of a grain bond. To estimate this error a plane was evaluated twice - first counting only the obvious grain bonds and second including all possible grain bonds - in both cases working within the given criteria. A difference of between 30 and $40 \%$ in the evaluations was found. Systematic errors should not affect comparisons between measurements made at the same time and with approximately the same degree of subjectivity.

The equality within experimental error of the evaluations on mutually perpendicular planes (Table I) proves that the grain bonds are randomly oriented and located. This is also true for the grains (through $L_{3}$ ) although there is a slight indication that the $L_{3}$ values on planes parallel to the deformation direction are higher than those on the perpendicular planes. This trend is understandable because the deformation direction is horizontal with respect to a vertical settling direction for the snow samples. Therefore the original needle and stellar crystals of the freshly sieved snow would lie with their smaller dimensions vertical (perpendicular to the deformation direction). The difference in $L_{3}$ values would indicate then that the equi-temperature metamorphism is not yet fully complete. The results for the three parallel planes for the first sample in Table I demonstrate that the errors due to inhomogeneity of the snow are of the same order as the errors of measurement. Furthermore, it is generally true that natural snow exhibits a much greater degree of inhomogeneity than laboratory-produced snow. Therefore, present errors are close to the limits expected for statistical measurements of snow structure.

The values of $\sigma(r) / \tilde{r}$ the relative standard deviation of the bond-size distribution are not reliable since they are essentially the difference between two nearly equal quantities. However, for these snows at least, the size distribution seems to be relatively narrow so that the average grain-bond size alone may be sufficient to characterize the bonding in the snow.

As part of a larger experiment, I 3 planes from I 3 other samples of rounded-grain snow were evaluated. The results of comparing measured values of $\mathcal{N}_{\mathrm{L}}$ with those calculated from Equation (I I) are shown in Figure 6 for these cases and the I I cases in Table I. The close agreement proves that the lines identified with grain bonds on the test plane can be said to belong to a family of disks in three dimensions. This justifies the concept of grain bonds as circular disks and the evaluation of their properties by these techniques.

The average number of grain bonds per grain in a snow sample is generally recognized as one of the most important parameters in the characterization of snow structure. However, values of this parameter cannot be accurately obtained from two-dimensional studies, either with thin sections or on a plane. Problems of overlapping and truncated images interfere with measurements on thin sections, whereas the irregular shape of snow grains only allows order of magnitude estimates of the number of grains per unit volume, and hence the number of grain bonds per grain. DeHoff and Rhines ( $196 \mathrm{I}$ ) show that the erroneous assumption of a particular shape can lead to errors of an order of magnitude or more in an estimate of the number of particles per unit volume.

The order of magnitude of the number of grains per unit volume is given, at least for the rounded-grain snow analysed in this paper, by assuming that the grains are all spheres of equal size. The radius of a sphere is linearly related to its mean intercept length. The requirement that the number of spheres per unit volume $\mathcal{N}_{\mathrm{vg}}$ multiplied by their mass equals the density of the snow yields

$$
\mathcal{N}_{\mathrm{vg}}=0.57 \rho /\left(\rho_{i} L_{3}{ }^{3}\right) .
$$

The number of grain bonds per grain for the data in Table $I$ is of the order of $I$.

Equation (14) is an over-estimate of the number of grains per unit volume if all grains have the same value of $L_{3}$ but different shapes. For a fixed mean intercept length, the symmetry of a sphere implies that it has the smallest volume (mass) of any shape, thereby generating the largest $\mathcal{N}_{\mathrm{vg}}$ (the multiplicative constant in Equation (I4) is shape dependent). 


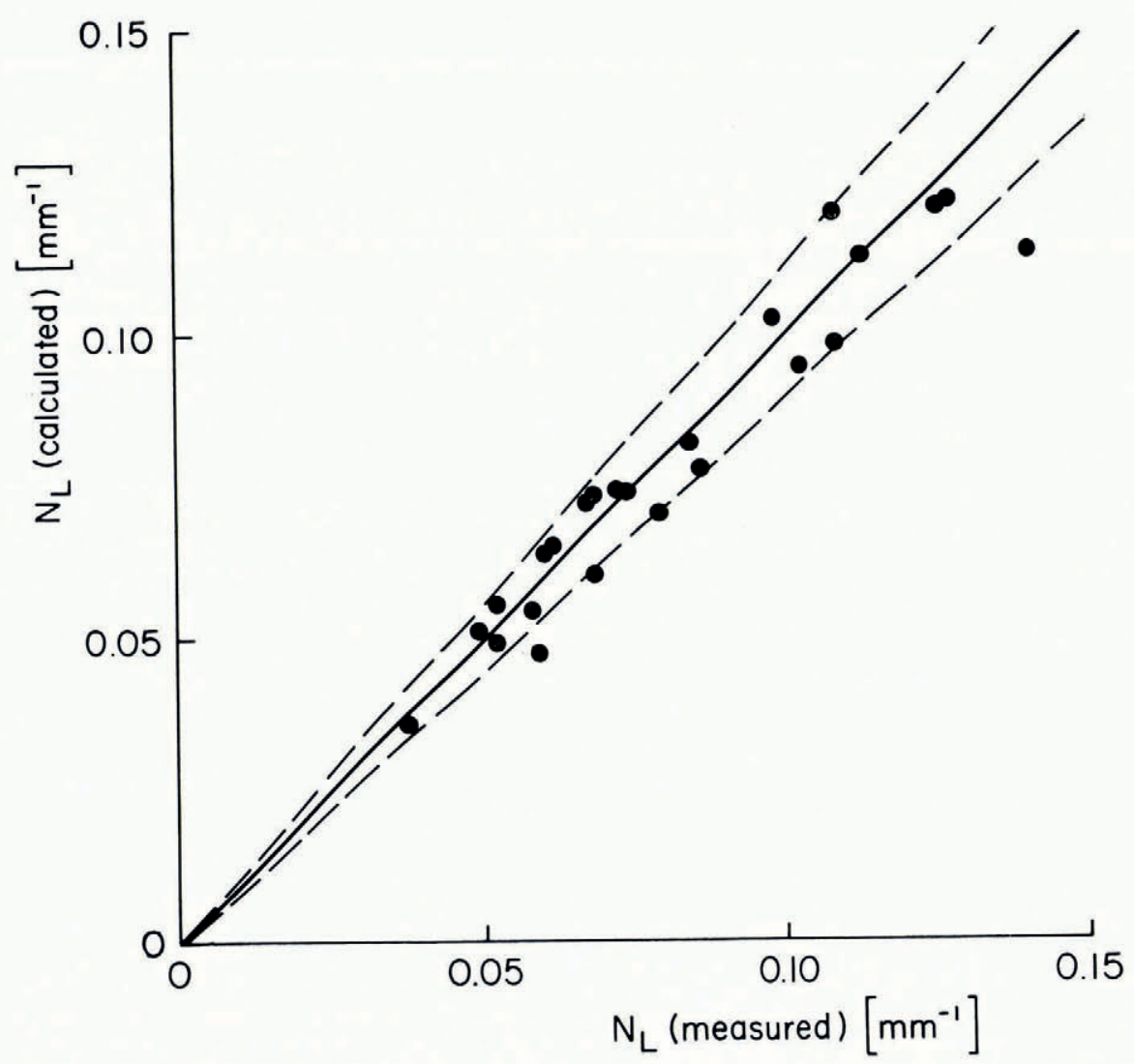

Fig. 6. Correspondence betzeen the number of grain bonds intersected per unit length of test line $\mathcal{N}_{\mathrm{L}}$ as measured by direct counting and as calculated from independent measurements, assuming the grain bonds to be disks.

The effect of a size distribution would cause Equation (14) to underestimate the true number of grains per unit volume. Equation (14) is based on the assumption that each grain has the same shape and size (same $L_{3}$ ). If a few, very large particles exist (as is common in snow), the measured $L_{3}$ will be larger than that corresponding to the most common grain size. The cubic dependence in Equation (14) will amplify this error and cause a severe underestimate of the number of grains per unit volume. Thus the two sources of errors for Equation (14) due to shape and size variations tend to cancel out.

The simple concept of equal-sized grains can be extended to provide a check on the order of magnitude of the contiguity. If spherical snow grains of equal size are assumed to be joined by circular disk grain-bonds of equal size, the number of grain bonds per grain $\mathcal{N}$ is related to the contiguity by the ratio of the radii of the sphere and the grain bond. For the data in Table I this ratio is constant, and the geometrical calculation yields

$$
C=0.036 \mathcal{N} \text {. }
$$

A value of order I for $\mathcal{N}$ is consistent with the $C$ values in Table I and with the calculation from Equation (14). 


\section{Summary AND CONCLUSIONS}

Criteria have been developed for the identification of grain bonds in snow structure. The underlying concepts of these criteria are based on the location of a grain bond in the neck region of two linked grains.

A technique has been described for the preparation of plane surfaces on which there is an outline of the ice in a snow sample.

These criteria and this technique have been combined with quantitative stereology in order to analyse samples of equi-temperature metamorphosed snow, thereby obtaining mean grain and grain-bond measurements.

For this type of snow the assumption that the grain bond has a disk shape has been validated. Grains and grain bonds were located and oriented sufficiently randomly (even after a $30 \%$ non-destructive deformation of the snow) that their characteristics could be deduced to within $\pm 10 \%$ from measurements on a single section plane. This error approached the limitation due to errors imposed by the inhomogeneity of snow. The agreement between densities measured on section planes (both parallel and perpendicular to the deformation direction) and densities measured by weighing samples indicated that the section planes prepared by the technique described here are truly representative of the bulk material.

The number of grain bonds per grain, recognized as an important snow structure parameter, cannot be determined from two-dimensional measurements because the number of grains per unit volume cannot be measured. Both the shape and size variations in grains cause errors of up to an order of magnitude. However, since these errors have opposite signs, reasonable estimates for the number of grains per unit volume can be made by assuming that all grains are spheres of equal size.

\section{Acknowledgements}

I am grateful to the National Research Council of Canada for its provision of a PostDoctoral Fellowship. Thanks are due to the Institute staff and Dr M. R. de Quervain for the support I received while working at the Weissfluhjoch.

MS. received 9 September 1974 and in revised form 21 February 1975

\section{REFERENCES} Ballard, G. E. H., and McGaw, R. W. 1965. A theory of snow failure. U.S. Cold Regions Research and Engineering
Laboratory. Research Report 137 .

DeHoff, R. T., and Rhines, F. N. 1961. Determination of number of particles per unit volume from measurements made on random plane sections: the general cylinder and the ellipsoid. Transactions of the Metallurgical Society of A.I.M.E., Vol. 221, p. 975-82.

Feldt, E. D., and Ballard, G. E. H. 1966. A theory of the consolidation of snow. Journal of Glaciology, Vol. 6, No. 43 , p. $145-57$. Fuchs, A. 1959. Some structural properties of Greenland snow. U.S. Snow, Ice and Permafrost Research Establish-
ment. Research Report 42 .

Fullman, R. L. I953. Measurement of particle sizes in opaque bodies. Transactions of the Metallurgical Society of
A.I.M.E., Vol. 197. p. 447-52.

Society of A.I.M.E., Vol. 212, p.

Keeler, C. M. 1969 . The growth of bonds and the increase of mechanical strength in a dry seasonal snow-pack. fournal of Glaciology, Vol. 8, No. 54, p. 441-50.

Narita, H. 197ı. Sekisetsu no hihyō-menseki no sokutei. II [Measurement of the specific surface of deposited snow. II]. Teion-kagaku: Low Temperature Science, Ser. A, [No.] 29, p. 69-79.

Quervain, M. R. de. I948. Das Korngefüge von Schnee. Mitteilungen des Eidg. Institutes für Schnee- und Lawinenforschung, Nr. 6.

Quervain, M. R. de. I969. Schneekundliche Arbeiten der Internationalen Glaziologischen Grönlandexpedition (Nivologie). Meddelelser om Gronland, Bd. $177, \mathrm{Nr} .4$. Sommerfeld, R. A., and LaChapelle, E. R. 1970. The classification of snow metamorphism. Fournal of Glaciology,
Vol. 9, No. 55, p. 3-1 7.

Underwood, E. E. 1970. Quantitative stereology. Reading. Mass., Addison-Wesley Publishing Co. 